Article

\title{
In Vitro Antifungal Activity of Sanguinarine and Chelerythrine Derivatives against Phytopathogenic Fungi
}

\author{
Xin-Juan Yang ${ }^{1,2, \dagger}$, Fang Miao ${ }^{2, \dagger}$, Yao Yao ${ }^{1}$, Fang-Jun Cao ${ }^{1}$, Rui Yang ${ }^{1}$, Yan-Ni Ma ${ }^{1}$, \\ Bao-Fu Qin ${ }^{2}$ and Le Zhou ${ }^{1, *}$ \\ 1 College of Science, Northwest A\&F University, Yangling 712100, Shaanxi, China; \\ E-Mails: yxjsn2@163.com (X.-J.Y.); mumu2006yo@126.com (Y.Y.); \\ caofangjun@yahoo.com.cn (F.-J.C.); yrer@126.com (R.Y.); ni-2003@163.com (Y.-N.M.) \\ 2 College of Life Science, Northwest A\&F University, Yangling 712100, Shaanxi, China; \\ E-Mails: miaofangmf@163.com (F.M.); baofu_qin@yahoo.com.cn (B.-F.Q.) \\ $\dagger$ These authors contributed equally to this work. \\ * Author to whom correspondence should be addressed; E-Mail: zhoulechem@yahoo.com.cn; \\ Tel.: +86-029-8709-2048; Fax: +86-029-8709-2226.
}

Received: 8 October 2012; in revised form: 29 October 2012 / Accepted: 30 October 2012 /

Published: 2 November 2012

\begin{abstract}
In order to understand the antifungal activity of some derivatives of sanguinarine (S) and chelerythrine $(\mathbf{C})$ and their structure-activity relationships, sixteen derivatives of $\mathbf{S}$ and $\mathbf{C}$ were prepared and evaluated for in vitro antifungal activity against seven phytopathogenic fungi by the mycelial growth rate method. The results showed that $\mathbf{S}, \mathbf{C}$ and their 6-alkoxy dihydro derivatives $\mathbf{S}_{\mathbf{1}}-\mathbf{S}_{\mathbf{4}}, \mathbf{C}_{\mathbf{1}}-\mathbf{C}_{\mathbf{4}}$ and 6-cyanodihydro derivatives $\mathbf{S}_{5}, \mathbf{C}_{5}$ showed significant antifungal activity at $100 \mu \mathrm{g} / \mathrm{mL}$ against all the tested fungi. For most tested fungi, the median effective concentrations of $\mathbf{S}, \mathbf{S}_{\mathbf{1}}, \mathbf{C}$ and $\mathbf{C}_{\mathbf{1}}$ were in a range of $14-50 \mu \mathrm{g} / \mathrm{mL}$. The structure-activity relationship showed that the $\mathrm{C}=\mathrm{N}^{+}$moiety was the determinant for the antifungal activity of $\mathbf{S}$ and $\mathbf{C} . \mathbf{S}_{\mathbf{1}}-\mathbf{S}_{\mathbf{5}}$ and $\mathbf{C}_{\mathbf{1}}-\mathbf{C}_{\mathbf{5}}$ could be considered as the precursors of $\mathbf{S}$ and $\mathbf{C}$, respectively. Thus, the present results strongly suggested that $\mathbf{S}$ and $\mathbf{C}$ or their derivatives $\mathbf{S}_{\mathbf{1}}-\mathbf{S}_{\mathbf{5}}$ and $\mathbf{C}_{\mathbf{1}}-\mathbf{C}_{\mathbf{5}}$ should be considered as good lead compounds or model molecules to develop new anti-phytopathogenic fungal agents.
\end{abstract}

Keywords: sanguinarine; chelerythrine; quaternary benzo[c]phenanthridine alkaloids; antifungal activity; phytopathogenic fungi 


\section{Introduction}

The continuing development of fungicidal resistance in plant and human pathogens necessitates the discovery and development of new fungicides. In the past decades, natural product-based plant protectants have attracted a lot of attention from researchers owing to the fact they are perceived to have lower environmental and mammalian toxicity [1].

Natural quaternary benzo[c]phenanthridine alkaloids (QBAs) constuitute a relative small class of isoquinoline alkaloids that nevertheless are widely distributed in the higher plant families Fumariaceae, Papaveraceae and Rutaceae [2,3]. Among QBAs, sanguinarine (S) and chelerythrine (C) (Figure 1) are the most common and their richest natural sources are the plants Sanguinaria Canadensis L., Dicranostigma lacucoides Hook.f. \& T. Thoms., Chelidonium majus L., Macleaya, Bocconia species from the Papaveraceae family and some members of Zanthoxylum (Rutaceae). In the past decades, QBAs had attracted much attention from investigators because of their extensive and important bioactivities, which include antitumour [4,5], antimicrobial [6-9], anti-inflammatory [10], antiviral [11], anti-HIV [12], antiparasitic action against Trichodina sp. [13], Dactylogyrus intermedius [14] and malaria [15], anti-platelet aggregation [16], anti-angiogenesis [17] and anti-acetylcholinesterase properties [18]. We recently also found that 1-alkoxydihydro derivatives of $\mathbf{S}$ had significant acaricidal activity against Psoroptes cuniculi [19].

Figure 1. Structures of sanguinarine (S) and chelerythrine (C).

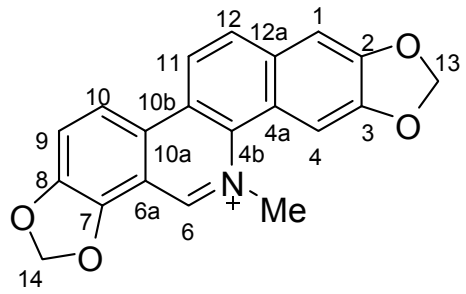

S<smiles></smiles>

C

Previous research had proven that $\mathbf{S}$ and $\mathbf{C}$ had significant activities against plant microbial pathogens. As early as in the period of 1939 to 1973, S had been found to be fungistatic on several plant fungal pathogens including Phytomatotrichum omnivorum, Sclerotium rolfisii, Gaeumannomyces grminis, Rhizoctonia solani, Amillaria mellea, Fusarium oxysyporum and Verticillium alboatrum [20-22]. In 1999, Matos et al. demonstrated that $\mathbf{S}$ and $\mathbf{C}$ were the active antifungal components of the plant extracts from Chelidonium majus L. or Macleaye cordata (Willd) R. Br. against 13 strains of phytopanthogenic fungi from the genus Fusarium [23]. The results were further confirmed by Liu et al. using bioassay-guided fractionation of the extract of Macleaya cordata $\mathrm{R}$. Br. [24]. In addition, the extract from Macleaye cordata (Willd) R. Br. was able to effectively control powdery mildew (Sphaerotheca pannosa var. rosae) of greenhouse roses in vivo [25]. However, until now the activity of the derivatives of $\mathbf{S}$ and $\mathbf{C}$ against phytopathogenic fungi and their structure-activity relationships were not reported. The objective of the present study was to systematically evaluate the antiphytopanthogenic fungal activity of a series of the derivatives of $\mathbf{S}$ and $\mathbf{C}$ and understand their structure-activity relationships. 


\section{Results and Discussion}

\subsection{Chemistry}

Compounds $\mathbf{S}$ and $\mathbf{C}$ were obtained by isolation from the entire plant of Macleaya microcarpa (Maxim) Fedde according to the method reported by us [26] and used as the starting materials to synthesize $\mathbf{S}_{\mathbf{1}}-\mathbf{S}_{\mathbf{8}}$ and $\mathbf{C}_{\mathbf{1}}-\mathbf{C}_{\mathbf{8}}$ (Figure 2), respectively, using the synthetic route outlined in Scheme 1.

Figure 2. Derivatives of sanguinarine $\mathbf{S}_{\mathbf{1}}-\mathbf{S}_{\mathbf{8}}$ and chelerythrine $\mathbf{C}_{\mathbf{1}}-\mathbf{C}_{\mathbf{8}}$.<smiles>[R]C1([R])c2c(ccc3c2OCO3)-c2ccc3cc4c(cc3c2N1C)OCO4</smiles>

$$
S_{1}-S_{8}
$$

$$
\begin{array}{ll}
\mathbf{S}_{1} & R=H, R^{\prime}=\mathrm{MeO} \\
\mathbf{S}_{2} & R=H, R^{\prime}=\mathrm{EtO} \\
\mathbf{S}_{3} & R=H, R^{\prime}=\mathrm{PrO} \\
\mathbf{S}_{4} & R=H, R^{\prime}=\text { iso-PrO } \\
\mathbf{S}_{5} & R=H, R^{\prime}=\mathrm{CN} \\
\mathbf{S}_{6} & R=H, R^{\prime}=\text { acetonyl } \\
\mathbf{S}_{7} & R=R^{\prime}=H \\
\mathbf{S}_{8} & R+R^{\prime}=\mathrm{O}
\end{array}
$$

Scheme 1. Synthetic pathway for compounds $\mathbf{S}_{\mathbf{1}}-\mathbf{S}_{\mathbf{8}}$ and $\mathbf{C}_{\mathbf{1}}-\mathbf{C}_{\mathbf{8}}$.<smiles>[R20]c1ccc2c(c1OC)C(C#N)N(C)c1c-2ccc2cc3c(cc12)OCO3</smiles>

Reagents and conditions: (a) $\mathrm{NaBH}_{4}, \mathrm{MeOH}$, r.t.; (b) $\mathrm{R}^{\prime} \mathrm{OH}, \mathrm{CuCl}_{2} \cdot 2 \mathrm{H}_{2} \mathrm{O}, 80{ }^{\circ} \mathrm{C}, 10 \mathrm{~h}$; (c) $\mathrm{NaCN}$, EtOH, r.t.; (d) Acetone, $\mathrm{Na}_{2} \mathrm{CO}_{3}$, reflux; $\left(\right.$ e) $\mathrm{K}_{3} \mathrm{Fe}(\mathrm{CN})_{6}, 1 \% \mathrm{HCl} / \mathrm{H}_{2} \mathrm{O}, 90{ }^{\circ} \mathrm{C}$.

Structural modifications of $\mathbf{S}$ and $\mathbf{C}$ included introduction of alkoxyl, cyano and acetonyl at C-6 by nucleophilic addition, and the reduction and oxidation of the $\mathrm{C}=\mathrm{N}$ double bond at the $\mathrm{C}-6$ position. Compounds $\mathbf{S}_{\mathbf{1}}-\mathbf{S}_{5} / \mathbf{C}_{\mathbf{1}}-\mathbf{C}_{5}$ and $\mathbf{S}_{\mathbf{6}}-\mathbf{S}_{8} / \mathbf{C}_{6}-\mathbf{C}_{\mathbf{8}}$ were prepared according to the methods recently reported by us $[19,26]$.

The structures of all compounds were elucidated by spectroscopic analyses including ESI-MS, ${ }^{1} \mathrm{H}-$ and ${ }^{13} \mathrm{C}-\mathrm{NMR}$ spectra. The spectral data of all the compounds were in agreement with that previously reported by us $[19,26]$. It should be noted that $\mathbf{S}_{\mathbf{1}}-\mathbf{S}_{\mathbf{6}}$ and $\mathbf{C}_{\mathbf{1}}-\mathbf{C}_{\mathbf{6}}$ were racemates and used as such for 
the bioactivity assays. We tried to resolve the racemates to their enantiomers but were unsuccessful. The main reason is that these compounds very easily convert back to their corresponding parent compounds $\mathbf{S}$ or $\mathbf{C}$ under acidic or even weakly acidic conditions.

\subsection{Antifungal Activity}

\subsubsection{Screening of Antifungal Activity in Vitro}

The in vitro antifungal activities of $\mathbf{S}, \mathbf{C}$ and their derivatives at a concentration of $100 \mu \mathrm{g} / \mathrm{mL}$ were assayed by the linear growth rate method. Thiabendazole (TBZ), a commercial fungicide, was used a control. The results are shown in Table 1.

Table 1. Linear Growth inhibitory rates (means \pm S.D.\%) of 18 compounds against seven phytopathogenic fungi $(100 \mu \mathrm{g} / \mathrm{mL})$.

\begin{tabular}{|c|c|c|c|c|c|c|c|}
\hline \multirow{2}{*}{ Compd. } & \multicolumn{7}{|c|}{ Seven Tested Phytopathogenic Fungi * } \\
\hline & C.L. & V.M. & F.S. & F.O.N. & F.O.V. & P. $O$. & A.A. \\
\hline $\mathbf{S}$ & 78.6 $\pm 3.4 \mathrm{DE} * *$ & $84.8 \pm 0.8 B C$ & $81.4 \pm 1.0 B C$ & $72.1 \pm 3.1 \mathrm{E}$ & $82.0 \pm 2.2 \mathrm{D}$ & $60.4 \pm 2.1 \mathrm{D}$ & $71.2 \pm 0.0 \mathrm{C}$ \\
\hline $\mathbf{S}_{1}$ & $\mathbf{8 0 . 8} \pm \mathbf{2 . 0 B C D E}$ & $88.1 \pm 0.4 \mathrm{AB}$ & $83.8 \pm 2.6 \mathrm{BC}$ & $86.6 \pm 1.5 \mathrm{C}$ & $84.0 \pm 0.0 C D$ & $70.8 \pm 2.1 C$ & $74.6 \pm 0.9 \mathrm{C}$ \\
\hline $\mathbf{S}_{2}$ & $87.5 \pm 2.8 \mathrm{~A}$ & $85.8 \pm 5.9 B C$ & $85.4 \pm 2.6 \mathrm{~B}$ & $69.7 \pm 1.7 \mathrm{E}$ & $85.6 \pm 1.6 C D$ & $70.1 \pm 3.2 C$ & $70.0 \pm 2.3 C$ \\
\hline $\mathbf{S}_{\mathbf{3}}$ & $86.1 \pm 0.8 \mathrm{AB}$ & $93.2 \pm 0.6 \mathrm{~A}$ & $86.9 \pm 4.6 \mathrm{AB}$ & $87.6 \pm 2.3 \mathrm{C}$ & $87.2 \pm 1.6 \mathrm{C}$ & $69.4 \pm 1.2 \mathrm{C}$ & $73.6 \pm 0.9 \mathrm{C}$ \\
\hline $\mathbf{S}_{4}$ & $78.1 \pm 1.5 \mathrm{DE}$ & $84.6 \pm 1.8 \mathrm{BC}$ & $82.0 \pm 2.1 B C$ & $79.6 \pm 5.4 \mathrm{D}$ & $84.5 \pm 1.0 \mathrm{CD}$ & $61.1 \pm 1.2 \mathrm{D}$ & $64.9 \pm 1.5 \mathrm{D}$ \\
\hline $\mathbf{S}_{5}$ & $79.7 \pm 0.8 \mathrm{CDE}$ & $80.1 \pm 0.4 C$ & $73.3 \pm 0.0 \mathrm{D}$ & $63.2 \pm 0.0 \mathrm{~F}$ & $71.6 \pm 0.7 \mathrm{E}$ & $47.0 \pm 0.6 \mathrm{E}$ & $44.9 \pm 1.6 \mathrm{E}$ \\
\hline$S_{6}$ & $19.1 \pm 2.0 \mathrm{HI}$ & $-4.0 \pm 3.5 \mathrm{FG}$ & $-0.1 \pm 3.2 \mathrm{~F}$ & $-0.5 \pm 0.9 \mathrm{~K}$ & $-4.4 \pm 0.9 \mathrm{~J}$ & $9.7 \pm 1.2 \mathrm{HI}$ & $16.2 \pm 1.5 \mathrm{H}$ \\
\hline $\mathbf{S}_{7}$ & $33.0 \pm 1.3 \mathrm{~F}$ & $-8.3 \pm 1.7 \mathrm{H}$ & $7.5 \pm 1.9 \mathrm{E}$ & $2.0 \pm 3.4 \mathrm{JK}$ & $-0.1 \pm 1.8 \mathrm{HI}$ & $20.8 \pm 0.0 \mathrm{G}$ & $21.2 \pm 0.9 \mathrm{G}$ \\
\hline $\mathbf{S}_{8}$ & $18.0 \pm 1.3 \mathrm{I}$ & $3.4 \pm 0.7 \mathrm{DE}$ & $6.3 \pm 0.7 \mathrm{E}$ & $0.5 \pm 0.9 \mathrm{JK}$ & $2.6 \pm 3.9 \mathrm{H}$ & $5.8 \pm 1.2 \mathrm{IJ}$ & $11.0 \pm 1.5 \mathrm{I}$ \\
\hline $\mathbf{C}$ & $\mathbf{8 1 . 5} \pm \mathbf{2 . 2} \mathrm{BCDE}$ & $88.5 \pm 2.0 \mathrm{AB}$ & $87.3 \pm 0.2 \mathrm{AB}$ & $85.6 \pm 0.9 \mathrm{C}$ & $94.2 \pm 0.0 \mathrm{~B}$ & $74.3 \pm 1.2 \mathrm{BC}$ & $83.7 \pm 1.8 \mathrm{~B}$ \\
\hline $\mathbf{C}_{1}$ & $\mathbf{7 9 . 9} \pm \mathbf{3 . 5 C D E}$ & $93.0 \pm 1.7 \mathrm{~A}$ & $92.4 \pm 0.4 \mathrm{~A}$ & $94.0 \pm 0.0 \mathrm{~B}$ & $100.0 \pm 0.0 \mathrm{~A}$ & $77.1 \pm 2.1 \mathrm{AB}$ & $\mathbf{8 5 . 8} \pm \mathbf{0 . 9} \mathrm{AB}$ \\
\hline $\mathrm{C}_{2}$ & $76.3 \pm 0.8 \mathrm{E}$ & $86.9 \pm 0.4 \mathrm{AB}$ & $83.4 \pm 0.2 B C$ & $100.0 \pm 0.0 \mathrm{~A}$ & $95.7 \pm 3.7 \mathrm{AB}$ & $79.9 \pm 1.2 \mathrm{AB}$ & $86.8 \pm 0.9 A B$ \\
\hline $\mathrm{C}_{3}$ & $85.7 \pm \mathbf{5 . 1} \mathrm{ABC}$ & $89.8 \pm 2.1 \mathrm{AB}$ & $86.4 \pm 6.4 \mathrm{AB}$ & $94.0 \pm 0.0 \mathrm{~B}$ & $100.0 \pm 0.0 \mathrm{~A}$ & $81.9 \pm 2.4 \mathrm{~A}$ & $87.3 \pm 0.9 \mathrm{AB}$ \\
\hline $\mathrm{C}_{4}$ & $82.6 \pm 4.0 A B C D$ & $83.5 \pm 0.8 B C$ & $82.2 \pm 0.9 B C$ & $90.5 \pm 0.9 \mathrm{BC}$ & $92.0 \pm 0.0 \mathrm{~B}$ & $83.0 \pm 0.6 \mathrm{~A}$ & $88.8 \pm 0.9 \mathrm{~A}$ \\
\hline $\mathrm{C}_{5}$ & $\mathbf{8 0 . 8} \pm \mathbf{0 . 3 B C D E}$ & $84.4 \pm 0.4 \mathrm{BC}$ & $\mathbf{7 8 . 7} \pm \mathbf{0 . 4 C D}$ & $40.2 \pm 3.4 G$ & $69.1 \pm 1.1 \mathrm{E}$ & $48.4 \pm 1.1 \mathrm{E}$ & $62.5 \pm 0.8 \mathrm{D}$ \\
\hline $\mathrm{C}_{6}$ & $5.7 \pm 3.4 \mathrm{~J}$ & $-1.4 \pm 2.8 \mathrm{EF}$ & $8.6 \pm 3.9 \mathrm{E}$ & $5.0 \pm 0.9 \mathrm{IJ}$ & $-3.3 \pm 3.3 \mathrm{IJ}$ & $1.4 \pm 2.4 \mathrm{~J}$ & $5.5 \pm 1.5 \mathrm{~J}$ \\
\hline $\mathrm{C}_{7}$ & $18.0 \pm 1.3 \mathrm{I}$ & $5.1 \pm 6.9 \mathrm{D}$ & $10.5 \pm 3.2 \mathrm{E}$ & $13.4 \pm 0.0 \mathrm{H}$ & $12.7 \pm 2.4 \mathrm{~F}$ & $28.9 \pm 5.9 \mathrm{~F}$ & $47.9 \pm 5.9 \mathrm{E}$ \\
\hline $\mathrm{C}_{8}$ & $24.0 \pm 2.0 \mathrm{GH}$ & $-5.2 \pm 2.4 \mathrm{FG}$ & $10.5 \pm 1.3 \mathrm{E}$ & $9.5 \pm 4.8 \mathrm{HI}$ & $6.8 \pm 0.9 \mathrm{G}$ & $11.9 \pm 1.3 \mathrm{H}$ & $24.7 \pm 1.8 \mathrm{G}$ \\
\hline $\mathrm{TBZ} * * *$ & $27.1 \pm 1.5 \mathrm{G}$ & $88.4 \pm 0.8 \mathrm{AB}$ & $83.9 \pm 3.5 \mathrm{BC}$ & $100.0 \pm 0.0 \mathrm{~A}$ & $100.0 \pm 0.0 \mathrm{~A}$ & $15.3 \pm 6.7 \mathrm{GH}$ & $30.6 \pm 4.0 \mathrm{~F}$ \\
\hline
\end{tabular}

* C.L.: Curvularia lunata; V.M.: Valsa mali; F.S.: Fusarium solani; F.O.V.: Fusarium oxysporum f. sp. vasinfectum; A.A.: Alternaria alternate; P.O.: Pyricularia oryza; F.O.N.: Fusarium oxysporum sp. niveum. ** The differences between data with different capital letters within a column are significant for the same tested fungus $(p<0.01)$ with respect to $\mathbf{S}$ and its pseudoalcoholates or $\mathbf{C}$ and its pseudoalcoholates. $* * *$ TBZ: thiabendazole.

The results in Table 1 show that among all the derivatives only the 6-alkoxydihydro derivatives $\mathbf{S}_{\mathbf{1}}-\mathbf{S}_{\mathbf{4}}$, $\mathbf{C}_{1}-\mathbf{C}_{4}$ and 6-cyanodihydro derivatives $\mathbf{S}_{5}, \mathbf{C}_{5}$ displayed significant activities $(40.2 \%-100 \%$ inhibitory rate) against all seven tested fungi at $100 \mu \mathrm{g} / \mathrm{mL}$. On the contrary, the other derivatives $\mathbf{S}_{\mathbf{6}}-\mathbf{S}_{\mathbf{8}}, \mathbf{C}_{\mathbf{6}}-\mathbf{C}_{\mathbf{8}}$ gave lower or no activity at the same concentration. With respect to C. lunata, P. oryzae and A. alternate, $\mathbf{S}, \mathbf{C}$ and all of their pseudoalcoholates (compounds $\mathbf{S}_{\mathbf{1}}-\mathbf{S}_{\mathbf{4}}, \mathbf{C}_{\mathbf{1}}-\mathbf{C}_{\mathbf{4}}$ ) were much more 
active than TBZ, a commercial fungicide $(p<0.01)$. For $V$. mali and $F$. solani, $\mathbf{S}, \mathbf{S}_{\mathbf{1}}-\mathbf{S}_{\mathbf{4}}, \mathbf{C}$ and $\mathbf{C}_{\mathbf{1}}-\mathbf{C}_{\mathbf{4}}$ showed the same activities as TBZ $(p>0.01)$. For $F$. oxysporum sp. niveum, $F$. oxysporum $\mathrm{f}$. $\mathrm{sp}$. vasinfectum, $P$. oryza, and $A$. alternate, the activities of $\mathbf{C}$ and its pseudoalcoholates $\mathbf{C}_{\mathbf{1}}-\mathbf{C}_{\mathbf{4}}$ were significantly stronger than that of $\mathbf{S}$ and its corresponding pseudoalcoholates $\mathbf{S}_{\mathbf{1}}-\mathbf{S}_{\mathbf{4}}(p<0.01)$. However, for the other three fungi, no significant differences between $\mathbf{S}$ or $\mathbf{S}_{\mathbf{1}}-\mathbf{S}_{\mathbf{4}}$ and $\mathbf{C}$ or $\mathbf{C}_{\mathbf{1}}-\mathbf{C}_{\mathbf{4}}$ was observed $(p>0.01)$. In addition, in most cases, there was also no significant difference between the activities of pseudoalcoholates $\mathbf{S}_{\mathbf{1}}-\mathbf{S}_{\mathbf{4}}$ or $\mathbf{C}_{\mathbf{1}}-\mathbf{C}_{\mathbf{4}}$ and their corresponding parent compound $\mathbf{S}$ or $\mathbf{C}$ and between the different pseudoalcoholates $\mathbf{S}_{\mathbf{1}}-\mathbf{S}_{\mathbf{4}}$ or $\mathbf{C}_{\mathbf{1}}-\mathbf{C}_{\mathbf{4}}$ from the same parent compound $\mathbf{S}$ or $\mathbf{C}(p<0.01)$.

\subsubsection{Antifungal Toxicity}

Based on the results above, $\mathbf{S}_{\mathbf{1}}$ and $\mathbf{C}_{\mathbf{1}}$ were used as representative pseudoalcoholates to further determine their regression equations and median effective concentration ( $\mathrm{EC}_{50}$ values) towards the seven tested fungi. $\mathbf{S}$ and $\mathbf{C}$ as parent compounds were used as control. The results are listed in Table 2. The inhibition rates of the four compounds increased as the concentration increased. All the compounds showed a significant linear correlation between the inhibition rate and log[concentration] value $\left(R^{2}\right.$ values $\left.=0.9193-0.9925, p<0.01\right)$. $\mathbf{C}$ and $\mathbf{C}_{1}$ gave the highest activity against $C$. lunata with $\mathrm{EC}_{50}$ values of $15.43 \mu \mathrm{g} / \mathrm{mL}(32.5 \mu \mathrm{M})$ and $14.23 \mu \mathrm{g} / \mathrm{mL}(37.5 \mu \mathrm{M})$, respectively, and $\mathbf{S}$ and $\mathbf{S}_{\mathbf{1}}$ showed the lowest activity against $P$. oryza with $\mathrm{EC}_{50}$ values of $101.6 \mu \mathrm{g} / \mathrm{mL}(2291.2 \mu \mathrm{M})$ and $96.63 \mu \mathrm{g} / \mathrm{mL}(265.9 \mu \mathrm{M})$. The other $\mathrm{EC}_{50}$ values were in a range of 24.28 to $53.8 \mu \mathrm{g} / \mathrm{mL}$. Comparison of the $\mathrm{EC}_{50}$ values of the four compounds for the same fungus showed that $\mathbf{C}$ and $\mathbf{C}_{\mathbf{1}}$ were more active than $\mathbf{S}$ and $\mathbf{S}_{\mathbf{1}}$ for C. lunata, F. solani, F. oxysporum sp. niveum, P. oryzae and A. alternate. However, for $F$. oxysporum f. sp. vasinfectum and $V$. mali, $\mathbf{S}$ and $\mathbf{S}_{\mathbf{1}}$ were more active than $\mathbf{C}$ and $\mathbf{C}_{\mathbf{1}}$. These results were not exactly the same as those obtained from Table 1 . This is because the various compounds had different slope values. On the other hand, compared the $\mathrm{EC}_{50}$ value $(\mu \mathrm{M})$ of $\mathbf{S}$ (or $\mathbf{C}$ ) with that of $\mathbf{S}_{\mathbf{1}}$ (or $\mathbf{C}_{\mathbf{1}}$ ) for the same fungi, it was found that in most cases $\mathbf{S}$ (or $\mathbf{C}$ ) was slightly more active than its correspongding pseudoalcoholate $\mathbf{S}_{\mathbf{1}}$ ( or $\mathbf{C}_{\mathbf{1}}$ ).

Besides $\mathrm{EC}_{50}$ value, the slope value $(k)$ in a toxicity regression equation is also an important factor for evaluation of bioactivity of a compound. A slope value reflects the concentration effect (CE) of a compound on its bioactivity. The $k$ values in Table 2 showed that the CEs of $\mathbf{S}, \mathbf{S}_{\mathbf{1}}, \mathbf{C}$ and $\mathbf{C}_{\mathbf{1}}$ on the activities against the seven fungi were different. In order to comprehensively compare the activities of the different compounds, the value of $k / \mathrm{EC}_{50}(\mathrm{nM})$ of each the compound, here named as comprehensive activity (CA), was calculated and shown in Table 2. Comparing the CA values of the compounds for each fungus, it may be obviously seen that for most of the fungi both $\mathbf{C}$ and $\mathbf{C}_{\mathbf{1}}$ were more active than $\mathbf{S}$ or $\mathbf{S}_{\mathbf{1}}$. However, the CAs of $\mathbf{S}$ or $\mathbf{C}$ were close to that of its pseudoalcoholate $\mathbf{S}_{\mathbf{1}}$ or $\mathbf{C}_{\mathbf{1}}$. This conclusion is basically consistent with that obtained from Table 1 . 
Table 2. Toxicity regression equations and $\mathrm{EC}_{50}$ values of compounds $\mathbf{S}, \mathbf{C}, \mathbf{S}_{\mathbf{1}}$ and $\mathbf{C}_{\mathbf{1}}$ against seven fungi.

\begin{tabular}{|c|c|c|c|c|c|c|c|}
\hline \multirow{2}{*}{ Fungus } & \multirow{2}{*}{ Compd. } & \multirow{2}{*}{$\begin{array}{c}\text { Toxicity regression } \\
\text { equation } *\end{array}$} & \multirow{2}{*}{$R^{2}$} & \multicolumn{2}{|c|}{ EC $_{50}$ value } & \multirow{2}{*}{$\begin{array}{c}\text { CI } 95 \% * * \\
(\mu \mathrm{g} / \mathrm{mL})\end{array}$} & \multirow{2}{*}{$\mathbf{C A} * * *$} \\
\hline & & & & $(\mu \mathrm{g} / \mathrm{mL})$ & $(\mu \mathbf{M})$ & & \\
\hline \multirow{4}{*}{ C.L. } & $\mathrm{S}$ & $y=0.5758 x-0.3905$ & 0.9628 & 35.20 & 76.6 & $35.13-35.27$ & 16.4 \\
\hline & $\mathrm{S}_{1}$ & $y=0.5452 x-0.2960$ & 0.9848 & 28.84 & 79.4 & $28.81-28.85$ & 18.9 \\
\hline & $\mathrm{C}$ & $y=0.3413 x+0.0944$ & 0.9621 & 15.43 & 32.5 & $15.21-15.65$ & 22.1 \\
\hline & $\mathrm{C}_{1}$ & $y=0.3635 x+0.0808$ & 0.9914 & 14.23 & 37.5 & $14.18-14.28$ & 25.5 \\
\hline \multirow{4}{*}{ V.M. } & $\mathrm{S}$ & $y=0.6317 x-0.3751$ & 0.9901 & 24.28 & 52.9 & $24.24-24.32$ & 26.0 \\
\hline & $\mathrm{S}_{1}$ & $y=0.5275 x-0.2329$ & 0.9860 & 24.51 & 67.5 & $23.97-25.05$ & 21.5 \\
\hline & $\mathrm{C}$ & $y=0.6918 x-0.6038$ & 0.9505 & 39.40 & 82.9 & $39.30-39.50$ & 17.6 \\
\hline & $\mathrm{C}_{1}$ & $y=0.6420 x-0.4423$ & 0.9904 & 29.36 & 77.4 & 29.34-29.38 & 21.9 \\
\hline \multirow{4}{*}{ F.S. } & $\mathrm{S}$ & $y=0.7415 x-0.6922$ & 0.9717 & 40.53 & 88.3 & $40.46-40.60$ & 18.3 \\
\hline & $\mathrm{S}_{1}$ & $y=0.5949 x-0.4189$ & 0.957 & 35.04 & 96.4 & $34.95-35.13$ & 17.0 \\
\hline & $\mathrm{C}$ & $y=0.5005 x-0.2123$ & 0.9600 & 26.50 & 55.8 & $26.41-26.59$ & 18.9 \\
\hline & $\mathrm{C}_{1}$ & $y=0.5949 x-0.3540$ & 0.9925 & 27.26 & 71.8 & $27.24-27.28$ & 21.8 \\
\hline \multirow{4}{*}{ F.O.N. } & S & $y=0.5139 x-0.3676$ & 0.9768 & 48.79 & 106.2 & $48.73-48.85$ & 10.9 \\
\hline & $\mathrm{S}_{1}$ & $y=0.5487 x-0.3317$ & 0.9705 & 32.79 & 90.2 & $32.73-32.85$ & 16.7 \\
\hline & $\mathrm{C}$ & $y=0.6186 x-0.4076$ & 0.9891 & 29.32 & 61.7 & 29.30-29.34 & 21.1 \\
\hline & $\mathrm{C}_{1}$ & $y=0.6629 x-0.4624$ & 0.9836 & 28.30 & 74.6 & $28.26-28.34$ & 23.4 \\
\hline \multirow{4}{*}{ F.O.V. } & $\mathrm{S}$ & $y=0.6007 x-0.4137$ & 0.9735 & 33.20 & 72.3 & $33.14-33.26$ & 18.1 \\
\hline & $\mathrm{S}_{1}$ & $y=0.6320 x-0.4735$ & 0.9826 & 34.70 & 95.5 & $34.66-34.74$ & 18.2 \\
\hline & $\mathrm{C}$ & $y=1.0309 x-1.2677$ & 0.9600 & 51.84 & 109.1 & $51.80-51.88$ & 19.9 \\
\hline & $\mathrm{C}_{1}$ & $y=0.6303 x-0.4308$ & 0.9684 & 29.98 & 79.0 & $29.91-30.06$ & 21.0 \\
\hline \multirow{4}{*}{ P.O. } & $\mathrm{S}$ & $y=0.3182 x-0.1386$ & 0.9687 & 101.6 & 221.2 & $101.2-102.00$ & 3.1 \\
\hline & $\mathrm{S}_{1}$ & $y=0.4238 x-0.3413$ & 0.9914 & 96.63 & 265.9 & $96.61-96.63$ & 4.4 \\
\hline & $\mathrm{C}$ & $y=0.7447 x-0.7550$ & 0.9727 & 48.44 & 101.9 & $48.41-48.47$ & 15.4 \\
\hline & $\mathrm{C}_{1}$ & $y=0.7178 x-0.6779$ & 0.9843 & 43.75 & 115.3 & $43.72-43.78$ & 16.4 \\
\hline \multirow{4}{*}{ A.A. } & $\mathrm{S}$ & $y=0.7921 x-0.8663$ & 0.9608 & 53.08 & 115.6 & $53.03-53.13$ & 14.9 \\
\hline & $\mathrm{S}_{1}$ & $y=0.5176 x-0.3453$ & 0.9193 & 43.47 & 119.6 & $43.10-43.84$ & 11.9 \\
\hline & $\mathrm{C}$ & $y=0.9270 x-1.0756$ & 0.9572 & 50.08 & 105.4 & $50.03-50.13$ & 18.5 \\
\hline & $\mathrm{C}_{1}$ & $y=0.6218 x-0.4104$ & 0.9659 & 29.11 & 76.7 & 29.04-29.18 & 21.4 \\
\hline
\end{tabular}

* $y$ : Inhibitory rate. $x$ : $\log _{10}[$ concentration $(\mathrm{mg} / \mathrm{L})]$; ** CI $95 \%$ : Confidence interval at $95 \%$ probability $(\mu \mathrm{g} / \mathrm{mL}) . * * *$ Slope value $/ \mathrm{EC}_{50}(\mu \mathrm{g} / \mathrm{mL}) \times 1,000$.

\subsection{Structure-Activity Relationship}

Unlike the parent compounds $\mathbf{S}$ or $\mathbf{C}$, all the derivatives of $\mathbf{S}$ or $\mathbf{C}$ lack the $\mathrm{C}=\mathrm{N}^{+}$moiety, and their only structural difference lies in their different substituents at the 6 position. $\mathbf{S}_{7}$ and $\mathbf{C}_{7}$ were the reduction products of $\mathbf{S}$ and $\mathbf{C}$, respectively. The significant difference of the activities between $\mathbf{S}$ and $\mathbf{S}_{7}$ or $\mathbf{C}$ and $\mathbf{C}_{7}$ showed that the iminium moiety in the molecule $\mathbf{S}$ or $\mathbf{C}$ is the determinant for their antifungal activity.

$\mathbf{S}_{1}-\mathbf{S}_{\mathbf{4}}$ or $\mathbf{C}_{1}-\mathbf{C}_{\mathbf{4}}$ have $N, O$-acetal structures and both $\mathbf{S}_{5}$ and $\mathbf{C}_{5}$ are structurally $\alpha$-hydroxynitrile derivatives. All these compounds are able to easily convert back to the corresponding parent compound $\mathbf{S}$ or $\mathbf{C}$ under acidic conditions [27,28], including the slightly acidic environment of the lysosome of cells [29]. Unlike $\mathbf{S}_{\mathbf{1}}-\mathbf{S}_{\mathbf{5}}$ and $\mathbf{C}_{\mathbf{1}}-\mathbf{C}_{\mathbf{5}}$, compounds $\mathbf{S}_{\mathbf{6}}-\mathbf{S}_{\mathbf{8}}$ and $\mathbf{C}_{\mathbf{6}}-\mathbf{C}_{\mathbf{8}}$ could not undergo a similar transformation under the same conditions. The significant difference in activities between $\mathbf{S}_{\mathbf{1}}-\mathbf{S}_{\mathbf{5}}$ and $\mathbf{S}_{6}-\mathbf{S}_{8}$ or between $\mathbf{C}_{1}-\mathbf{C}_{5}$ and $\mathbf{C}_{6}-\mathbf{C}_{8}$ as well as the lack of a significant difference between the of 
$\mathbf{S}_{\mathbf{1}}-\mathbf{S}_{\mathbf{5}}$ or $\mathbf{C}_{\mathbf{1}}-\mathbf{C}_{\mathbf{5}}$ strongly suggest that the activities of $\mathbf{S}_{\mathbf{1}}-\mathbf{S}_{\mathbf{5}}$ and $\mathbf{C}_{\mathbf{1}}-\mathbf{C}_{\mathbf{5}}$ might well come from their corresponding hydrolytic products, i.e., $\mathbf{S}$ or $\mathbf{C}$. In other words, $\mathbf{S}$ and $\mathbf{C}$ might be the real active compounds of $\mathbf{S}_{\mathbf{1}}-\mathbf{S}_{\mathbf{5}}$ and $\mathbf{C}_{\mathbf{1}}-\mathbf{C}_{\mathbf{5}}$, respectively, while $\mathbf{S}_{\mathbf{1}}-\mathbf{S}_{\mathbf{5}}$ and $\mathbf{C}_{\mathbf{1}}-\mathbf{C}_{\mathbf{5}}$ might be only the precursors of $\mathbf{S}$ and $\mathbf{C}$. In addition, comparing the activities of $\mathbf{C}$ with that of $\mathbf{S}$ or $\mathbf{C}_{\mathbf{1}}-\mathbf{C}_{\mathbf{5}}$ with $\mathbf{S}_{\mathbf{1}}-\mathbf{S}_{\mathbf{5}}$, we could find that for most of the fungi, a 7,8-methoxy group, relative to a 7,8-methylenedioxy group, could enhance the activity to a certain degree. It was worth noting that the structure and antifungal activity relationships were very similar to the case of their reported antibacterial activities [26].

\section{Experimental}

\subsection{General}

Sanguinarine iodide $(\mathbf{S})$ and chelerythrine iodide $(\mathbf{C})$ were obtained in our laboratory by isolation from the whole plant of M. microcarpa (Maxim) Fedde [24]. Melting points (m.p.) were determined on XT-4 micro-melting point apparatus and are uncorrected. ${ }^{1} \mathrm{H}-\mathrm{NMR}$ and ${ }^{13} \mathrm{C}-\mathrm{NMR}$ spectra were recorded with a Bruker AVANCE III instrument operating at 500 and $125 \mathrm{MHz}$, respectively, using TMS as an internal standard. ESI-MS was measured on a Trace mass spectrometer. Thiabendazole (TBZ, $\geq 99.1 \%$ ), a commercial fungicide standard, was purchased from Sigma-Aldrich Trading Co. Ltd. (Shanghai, China). Dimethyl sulfoxide (DMSO) was purchased from J\&K China Chemical Ltd. (Beijing, China). Other reagents were obtained locally and of analytical grade. The water used was redistilled and ion-free. Curvularia lunata, Alternaria alternate, Fusarium solani, Fusarium oxysporum sp. vasinfectum, Valsa mali, Fusarium oxysporum sp. niveum and Pyricularia oryzae were isolated, identified and provided by the Center of Pesticide Research, Northwest A\&F University, (Shaanxi, China). These fungi were grown on PDA plates at $28{ }^{\circ} \mathrm{C}$ and maintained by periodic subculturing at $4{ }^{\circ} \mathrm{C}$.

\subsection{Synthesis of $\mathbf{S}_{\mathbf{1}}-\mathbf{S}_{\mathbf{8}}$ and $\mathbf{C}_{\mathbf{1}}-\mathbf{C}_{\mathbf{8}}$}

Compounds $\mathbf{S}_{\mathbf{1}}-\mathbf{S}_{\mathbf{5}}$ and $\mathbf{C}_{\mathbf{1}}-\mathbf{C}_{\mathbf{5}}$ were prepared according to the methods and the procedure recently reported by us [19]. Compounds $\mathbf{S}_{6}-\mathbf{S}_{\mathbf{8}}$ and $\mathbf{C}_{6}-\mathbf{C}_{\mathbf{8}}$ were prepared the procedure according to the methods previously reported by us [26]. The spectral data of $\mathbf{S}_{1}-\mathbf{S}_{\mathbf{8}}$ and $\mathbf{C}_{1}-\mathbf{C}_{\mathbf{8}}$ are consistent with our previous papers $[19,26]$.

\subsection{Screening of Antifungal Activity in Vitro}

The antifungal activity in vitro was assayed by the growth rate method [30] with slight modifications. The tested fungi maintained on potato-dextrose-agar (PDA) medium slants were subcultured for $48 \mathrm{~h}$ in Petri dishes prior to testing and used for inoculation of fungal strains on PDA plates. The tested compounds were completely dissolved in DMSO, and then diluted by water to provide the stock solution $(1.0 \mu \mathrm{g} / \mathrm{mL})$ in $5 \%$ DMSO aqueous solution. The stock solution was completely mixed with the autoclaved PDA medium to provide a medium containing $100 \mu \mathrm{g} / \mathrm{mL}$ of sample and then poured into the Petri dishes in a laminar flow chamber. Thiabendazole solution $(1.0 \mu \mathrm{g} / \mathrm{mL})$ in 5\% DMSO aqueous solution and 5\% DMSO aqueous solution were used as the treated control and the untreated control, respectively. When the medium in the plates was partially solidified, 
a 5-mm thick and 4-mm diameter disc of fungus cut from earlier subcultured Petri dishes was placed at the centre of the semi-solid medium. The dishes were kept in an incubator at $28{ }^{\circ} \mathrm{C}$ for $72 \mathrm{~h}$. Each experiment was carried out in triplicates. The diameters (in $\mathrm{mm}$ ) of inhibition zones were measured in three different directions and the growth inhibition rates were calculated according to the following formula and expressed as means \pm S.D.:

$$
\text { Growth inhibition rate }(\%)=\left[\left(d_{\mathrm{c}}-d_{0}\right)-\left(d_{\mathrm{s}}-d_{0}\right)\right] /\left(d_{\mathrm{c}}-d_{0}\right) \times 100
$$

where $d_{0}$ : Diameter of the fungus cut, $d_{\mathrm{c}}$ : Diameter of the untreated control fungus, $d_{\mathrm{s}}$ : Diameter of the sample-treated fungus.

\subsection{Toxicity Assays}

Based on in vitro antifungal activity screening results, $\mathbf{S}, \mathbf{S}_{\mathbf{1}}, \mathbf{C}$ and $\mathbf{C}_{\mathbf{1}}$ were selected to determine their toxicity. According to the method described above, a stock solution containing $800 \mu \mathrm{g} / \mathrm{mL}$ samples was prepared in 5\% DMSO aqueous solution. Then the stock solution was completely mixed with the autoclaved PDA medium to prepare a set of media containing 120, 90, 80, 40, 20, 10, 5 and $2.5 \mu \mathrm{g} / \mathrm{mL}$ samples, respectively. 5\% DMSO aqueous solution was used as the untreated control. According to the method described above, the antifungal activity for each concentration was determined. Each experiment was carried out in triplicate. The average inhibition rate for each test was calculated. The concentration of the compound was transformed to the corresponding logarithm value $\left(\log _{10} C\right)$. A linear regression, namely toxicity regression equation, was established by using the least square method. $\mathrm{EC}_{50}$ values were calculated from the toxicity regression equation.

\subsection{Statistic Analysis}

SPSS statistics V17.0 software was used to analyze the data and establish toxicity regression equationa. Duncan multiple comparison test was performed on the data to determine significant differences between the inhibition rates of different compounds at the same concentration.

\section{Conclusions}

In this study, sixteen derivatives of $\mathbf{S}$ and $\mathbf{C}$ were obtained by modification of their $\mathrm{C}=\mathrm{N}^{+}$groups and evaluated for in vitro antifungal activity against seven phytopathogenic fungi by the mycelial growth rate method. The structure-activity relationships were also discussed. $\mathbf{S}, \mathbf{C}, \mathbf{S}_{\mathbf{1}}-\mathbf{S}_{\mathbf{5}}$ and $\mathbf{C}_{\mathbf{1}}-\mathbf{C}_{\mathbf{5}}$ showed significant antifungal activities against all the tested fungi at $100 \mu \mathrm{g} / \mathrm{mL}$. For most tested fungi, the median effective concentrations of $\mathbf{S}, \mathbf{S}_{\mathbf{1}}, \mathbf{C}$ and $\mathbf{C}_{\mathbf{1}}$ were in a range of $14-50 \mu \mathrm{g} / \mathrm{mL}$. The iminium bond was proven to be the determinant for the antifungal activity of $\mathbf{S}$ and $\mathbf{C}$. $\mathbf{S}_{\mathbf{1}}-\mathbf{S}_{\mathbf{5}}$ and $\mathbf{C}_{\mathbf{1}}-\mathbf{C}_{\mathbf{5}}$ were considered as the precursors of $\mathbf{S}$ and $\mathbf{C}$, respectively. Based on the present results, $\mathbf{S}$ and $\mathbf{C}$ should be considered as good lead compounds or model molecules to develop new anti-phytopathogenic fungal agents.

\section{Acknowledgments}

This project was supported by the National Natural Science Foundation of China (NNSF; Nos. $31172365,31000865)$. 


\section{References}

1. Wedge, D.E.; Camper, N.D. Biologically Active Natural Products. In Agrochemicals and Pharmaceuticals; Cutler, H.G., Cutler, S.J., Eds.; CRC Press: Boca Raton, FL, USA, 2000; pp. 1-15.

2. Krane, B.D.; Fagbule, M.O.; Shamma, M.; Gözler, B. The benzophenanthridine alkaloids. J. Nat. Prod. 1984, 47, 1-43.

3. Šimánek, V. Benzophenanthridine Alkaloids. In The Alkaloids; Brossi, A., Ed.; Academic Press: New York, NY, USA, 1985; Volume 26, pp. 185-240.

4. Ahsan, H.; Reagan-Shaw, S.; Breur, J.; Ahmad, N. Sanguinarine induces apoptosis of human pancreatic carcinoma AsPC-1 and BxPC-3 cells via modulations in Bcl-2 family proteins. Cancer Lett. 2007, 249, 198-208.

5. Jang, B.C.; Park, J.G.; Song, D.K.; Baek, W.K.; Yoo, S.K.; Jung, K.H.; Park, G.Y.; Lee, T.Y.; Suh, S.I. Sanguinarine induces apoptosis in A549 human lung cancer cells primarily via cellular glutathione depletion. Toxicol. In Vitro 2009, 23, 281-287.

6. Godowski, K.C. Antimicrobial action of sanguinarine. J. Clin. Dent. 1989, 1, 96-101.

7. Navarro, V.; Villarreal, M.L.; Rojas, G.; Lozoya, X. Antimicrobial evaluation of some plants used in Mexican traditional medicine for the treatment of infectious diseases. J. Ethnopharmacol. 1996, 53, 143-147.

8. Zuo, G.Y.; Meng, F.Y.; Hao, X.Y.; Zhang, Y.L.; Wang, G.C.; Xu, G.L. Antibacterial alkaloids from Chelidonium majus Linn (Papaveraceae) against clinical isolates of methicillin-resistant Staphylococcus aureus. J. Pharm. Pharmaceut. Sci. 2008, 11, 90-94.

9. Meng, F.Y.; Zuo, G.Y.; Hao, X.Y.; Wang, G.C.; Xiao, H.T.; Zhang, J.Q.; Xu, G.L. Antifungal activity of the benzo[c]phenanthridine alkaloids from Chelidonium majus Linn against resistant clinical yeast isolates. J. Ethnopharmacol. 2009, 125, 494-496.

10. Lenfeld, J.; Kroutil, M.; Maršálek, E.; Slavík, J.; Preininger, V.; Šimánek, V. Antiinflammatory activity of quaternary benzophenanthridine alkaloids from Chelidonoum majus. Planta Med. 1981, 43, 161-165.

11. Colombo, M.L.; Bosisio, E. Pharmacological activities of Chelidonium majus L. (Papaveraceae). Pharmacol. Res. 1996, 33, 127-134.

12. Tan, G.T.; Pezzuto, J.M.; Kinghorn, A.D.; Hughes, S.H. Evaluation of natural products as inhibitors of human immunodeficiency virus type 1 (HIV-1) reverse transcriptase. J. Nat. Prod. 1991, 54, 143-154.

13. Yao, J.Y.; Li, X.L.; Shen, J.Y.; Pan, X.Y.; Hao, G.J.; Xu, Y.; Ying, W.L.; Ru, H.S.; Liu, X.L. Isolation of bioactive components from Chelidonium majus L. with activity against Trichodina sp. Aquaculture 2011, 318, 235-238.

14. Wang, G.X.; Zhou, Z.; Jiang, D.X.; Han, J.; Wang, J.F.; Zhao, L.W.; Li, J. In vivo anthelmintic activity of five alkaloids from Macleaya microcarpa (Maxim) Fedde against Dactylogyrus intermedius in Carassius auratus. Vet. Parasitol. 2010, 171, 305-313.

15. Nyangulu, J.M.; Hargreaves, S.L.; Sharples, S.L.; Mackay, S.P.; Waigh, R.D.; Duval, O.; Mberu, E.K.; Watkins, W.M. Antimalarial benzo[c]phenanthridines. Bioorg. Med. Chem. Lett. 2005, 15, 2007-2010.

16. Tsai, I.L.; Wun, M.F.; Teng, C.M.; Ishikawa, T.; Chen, I.S. Anti-platelet aggregation constituents from formosan Toddalia asiatica. Phytochemistry 1998, 48, 1377-1382. 
17. Eun, J.P.; Koh, G.Y. Suppression of angiogenesis by the plant alkaloid, sanguinarine. Biochem. Biophys. Res. Commun. 2004, 317, 618-624.

18. Cho, K.M.; Yoo, I.D.; Kim, W.G. 8-Hydroxy dihydrochelerythrine and 8-hydroxy dihydrosanguinarine with a potent acetylcholinesterase inhibitory activity from Chelidonium majus L. Biol. Pharm. Bull. 2006, 29, 2317-2320.

19. Miao, F.; Yang, X.J.; Ma, Y.N.; Zheng, F.; Song, X.P.; Zhou, L. Structural modification of sanguinarine and chelerythrine and their in vitro acaricidal activity against Psoroptes cuniculi. Chem. Pharm. Bull. 2012, doi:10.1248/cpb.12-00618.

20. Greathouse, G.A. Alkaloids from Sanguinaria canadensis and their influence on growth of Phymatotrichum omnivorum. Plant Physiol. 1939, 14, 377-380.

21. Presley, J. Growth response of Verticillium albo-atrum to sanguinarine in nutrient agar. Phytopathology 1969, 59, 1968-1969.

22. Howell, C.R.; Bell, A.A.; Stipanovic, R.D. Virulence to cotton and tolerance to sanguinarine among Verticillium species. Can. J. Microbiol. 1973, 19, 1367-1371.

23. Matos, O.C.; Baeta, J.; Silva, M.J.; Pinto Ricardo, C.P. Sensitivity of Fusarium strains to Chelidonium majus L. extracts. J. Ethnopharmacol. 1999, 66, 151-158.

24. Liu, H.; Wang, J.; Zhao, J.; Lu, S.; Wang, J.; Jiang, W.; Ma, Z.; Zhou, L. Isoquinoline alkaloids from Macleaya cordata active against plant microbial pathogens. Nat. Prod. Commun. 2009, 4, 1557-1560.

25. Newman, S.E.; Roll, M.J.; Harkrader, R.J. A naturally occurring compound for controlling powdery mildew of greenhouse roses. HortScience 1999, 34, 686-689.

26. Miao, F.; Yang, X.J.; Zhou, L.; Hu, H.J.; Zheng, F.; Ding, X.D.; Sun, D.M.; Zhou, C.D.; Sun, W. Structural modification of sanguinarine and chelerythrine and their antibacterial activity. Nat. Prod. Res. 2011, 25, 863-875.

27. Dostál, J.; Slavík, J. Some Aspects of the Chemistry of Quaternary Benzo[c]phenanthridine Alkaloids. In Studies in Natural Products Chemistry, 1st ed.; Atta-ur-Rahman, Ed.; Elsevier Scicence B.V: Oxford, UK, 2002; Volume 27, Part H, pp. 155-184.

28. Slavík, J.; Hanuš, V.; Slavíková, L. Alkaloids from Stylophorum lasiocarpum (Oliv.) Fedde. Collec. Czech. Chem. Commun. 1991, 56, 1116-1122.

29. Walterová, D.; Ulrichová, J.; Válka, I.; Vicar, J.; Vavrecková, C.; Táborská, E.; Harjrader, R.J.; Meyer, D.L.; Cerná, H.; Simánek, V. Benzo[c]phenanthridine alkaloids sanguinarine and chelerythrine: Biological activities and dental care applications. Acta Univ. Palacki. Olomuc. Fac. Med. 1995, 139, 7-16.

30. Zhang, J.W.; Li, S.K.; Wu, W.J. The main chemical composition and in vitro antifungal activity of the essential oils of Ocimum basilicum Linn. var. pilosum (Willd.) Benth. Molecules 2009, 14, $273-278$.

Sample Availability: Samples of the compounds $\mathbf{S}_{\mathbf{1}}-\mathbf{S}_{\mathbf{8}}$ and $\mathbf{C}_{\mathbf{1}}-\mathbf{C}_{\mathbf{8}}$ are available from the authors.

(C) 2012 by the authors; licensee MDPI, Basel, Switzerland. This article is an open access article distributed under the terms and conditions of the Creative Commons Attribution license (http://creativecommons.org/licenses/by/3.0/). 